\title{
HOW CLASSROOM ACOUSTICS INFLUENCE STUDENTS AND TEACHERS: A SYSTEMATIC LITERATURE REVIEW
}

\author{
Jordi Mogas-Recalde (D), Ramon Palau (D), Marian Márquez (iD) \\ Universitat Rovira i Virgili (Spain) \\ jordi.mogas@urv.cat,ramon.palan@urv.cat,marian.marque@urv.cat
}

Received August 2020

Accepted February 2021

\section{Abstract}

Acoustics in schools have been studied during years, but nowadays there are more possibilities than ever before to introduce improvements. This study presents a systematic literature review determining what acoustic parameters are present in classrooms and how they affect both teachers and students. Following the analysis, we put forward a two-block classification: the physical parameters of the sound or noise in the classroom and the consequences of the acoustics on the people in the classroom. Advances in the design of learning spaces and the use of technologies ranging from devices and green material to advanced automation systems make it possible to direct acoustic solutions toward smarter learning spaces. This review also highlights the acoustic parameters to consider in smart classrooms (noise, reverberation, speech transmission and speech clarity) and the main effects of acoustics on teachers and students. Some conclusions and recommendations are drawn, but more research is needed in terms of school improvement considering acoustics influence and smart classrooms possibilities.

Keywords - Classroom, smart classroom, acoustics, classroom acoustics, educational acoustics, noise.

\section{To cite this article:}

Mogas-Recalde, J., Palau, R., \& Márquez, M. (2021). How classroom acoustics influence students and teachers: A systematic literature review. Journal of Technology and Science Education, 11(2), 245-259. https://doi.org/10.3926/jotse.1098

\section{Introduction}

Physical learning spaces are evolving much faster than ever before. Until few ago, classrooms used to be rooms with chairs and tables arranged in rows facing a blackboard from where the teacher gave master classes with no interaction. Currently new learning methodologies and new pedagogical orientations are being incorporated into teaching practices, especially boosting cooperation, debate and centering learning on the student regardless the size of the classes (Wang \& Zhang, 2019), but such educational innovation is mostly placed in the old and rigid physical disposition of traditional classrooms. Modernisation is being proposed in a number of cases by designing more flexible spaces to learn, with more engaging furniture, wheeled chairs, multiuse spaces, diversifying learning landscapes and so forth (JISC, 2006; Lehtniemi, 2016; Bosch, 2018), but normally not considering technology advances in an efficient way nor regulating environmental factors such as acoustic parameters to provide the necessary conditions for a good performance (Palau \& Mogas, 2019). 
Learning does not happen only in classrooms. Formal learning is the basis for all students, but it is combined with non-formal and informal ubiquitous learning, as students complement schooling with loads of inputs from the internet and other personal contexts, anytime and everywhere (Kinshuk \& Graf, 2012). Also, within the school buildings learning started to be considered ubiquitous, and students learn not only from teachers, but also in their interaction with peers in the spare time, checking their mobile phones to augment the experience with virtual information, and customizing what they learn according to their goals, interests, preferences, personal cognitive background, and the context (Kinshuk \& Graf, 2012). Open spaces to learn lead to the Smart Learning Environments (SLE), increasingly studied in the last decade, which cope with these new needs for education. SLE consist on spaces enriched with digital, adaptive and environment-aware devices in order to promote faster and better learning (Koper, 2014) and to provide better work conditions for teachers (Mogas, Palau, Lorenzo \& Gallon, 2020). In SLE, technology must be integrated to enhance learning from the pedagogical strategy and the formative needs of the students (López, 2019).

While SLE and smart classrooms present possibilities to improve teaching and learning, smart classrooms offer further special potentialities that open spaces cannot control alike. Concretely, smart classrooms offer the possibility to track parameters of environmental factors and propose some sort of regulation to acquire the most suitable conditions (Palau \& Mogas, 2019). Environmental factors refer to lighting, temperature, air quality and acoustics, and all of these are proven to affect teaching and learning processes (Palau \& Mogas, 2019), being acoustics one of the factors with greater impact in learning performance and teacher well-being. Acoustics may affect communication due to diverse adverse conditions with origin on the speaker, on the listener limitations, or caused by the environment (degradation with energetic masking, noise, background babble, reverberation) (Mattys, Davis, Bradlow \& Scott, 2012). Adverse acoustics require more effortful listening (Peng \& Wang, 2019), which can imply student poorer performance. Various outdoor and indoor sources of sound may impact on the students' learning processes (Dockrell \& Shield, 2012; Santos, Ramos \& Seligman, 2013), listening (Woolner \& Hall, 2010) and behavior (Prodi \& Visentin, 2015), on the teacher's voice (Mendes, Lucena, De Araújo, Melo, Lopes \& Silva, 2016) and health (Hadzi-Nikolova, Mirakovski, Zdravkovska, Angelovska \& Doneva, 2013; Tiesler, Machner, \& Brokmann, 2015), and on communication between students and teachers or among students (Sekine, Asai \& Egi, 2018). Health problems in teachers appear in terms of hoarseness, dryness or other voice problems, while bad acoustics could represent in students a worsening of hyperacusis, tinnitus and hearing loss. In addition, in a well-designed classroom, students with special needs and disabilities such as deafness and autism may find a more inclusive and suitable space to learn (Bezerra \& Gaudiot, 2012; Kanakri, Shepley, Varni \& Tassinary, 2017; van der Kruk, Wilson, Palghat, Downing, Harper-Hill \& Ashburner, 2017; Mogas, Palau, Sanromà \& Lázaro, 2019).

Technological solutions for smart classrooms are being developed along with the Fourth Industrial Revolution (4IR). The 4IR introduces in education Big Data, Artificial Intelligence, Internet of Things and other possibilities (Zhong, Xu, Klotz \& Newman, 2017), making it possible to improve the personalisation of learning experiences and offering a much more effective teaching system (Mogas et al., 2020). By using the mentioned advances or less complex solutions, controlling acoustics in smart classrooms appear in the form of systems for improving sound quality and reducing noise (Russo \& Ruggiero, 2018), systems for giving teachers insights into current needs (Jayahari, Beenu \& Bijlani, 2017), devices for controlling sound exposure (Guntha, Hariharan \& Rangan, 2016) and designs aimed at providing greener and more sustainable settings (Tahsildoost \& Zomorodian, 2018; Trematerra \& Lombardi, 2017; Iannace, Trematerra \& Trematerra, 2014). Indeed, sustainability also plays a key role in acoustics for smart classrooms (Roy, 2010). Future solutions will work toward the automation of certain processes (Mogas et al., 2020). These technological advances with a better understanding of teachers, students and the environment will enable classrooms to be smarter in the new era (Shahroom \& Hussin, 2018).

The influence of the sound environment on performance is a worry in classrooms, but there is lack of evidence regarding the effectiveness of strategies to control the sound environment by room acoustic 
design (Reinten, Braat-Eggen, Hornikx, Kort \& Kohlrausch, 2017). The main aim of this paper was to determine what acoustic parameters are present in smart classrooms and how they affect teachers and students. This study was necessary as classroom acoustics have been treated from different approaches, but studies coping with how smart classrooms must consider acoustics for its development are still scarce. To this end a review of studies published on the Web of Science (WoS) and Scopus was carried out. Following an analysis of the papers retrieved, a two-block classification is proposed: the first comprises studies on the physical parameters of sound or noise in the classroom, and the second, the effects of acoustics and noise on the people inside the classroom (i.e. teachers and students). A final section devoted to discussion and conclusions interrelates different aspects appeared throughout this work and may help in decision-making for smart classroom design and their understanding in terms of acoustics.

\section{Method}

\subsection{Literature Search}

In education it is usual to perform theoretical revisions not following a systematic process, which leads to generate theories with no consistent foundation (Esteve, Duch \& Gisbert, 2014). According to Gisbert and Bonfill (2004), systematic reviews are considered scientific investigations as they are intended to be rigorous, informative, exhaustive, and explicit. Through systematic literature reviews, the process of searching, compiling, and evaluating the obtained information is specified in detail and, likewise, it is possible to repeat them to verify the results and conclusions reached. The results in such process are more reliable than those of the so-called narrative reviews, which do not accomplish the desired scientific criteria.

In order to develop our systematic review, the steps indicated by the aforementioned authors have been followed, which are based on the Cochrane Collaborators' "Manual of reviewers" (Gisbert \& Bonfill, 2004: page 32). More concretely, we respected the concretion presented in Vangrieken, Meredith, Packer, and Kyndt (2017). Two main databases in educational science were consulted: Web of Science (WoS) and Scopus. The literature search was aimed to retrieve all the documents studying all forms of classroom acoustics in order to get an overall understanding of all the focuses. This holistic view is useful for identifying possible third intervening variables in further studies. The searches were performed using three combinations of keywords: (1) acoustics "learning processes", (2) acoustics "learning environment", and (3) classroom acoustics.

\subsection{Selection Criteria and Selection Process}

The first phase of the systematic review included papers published in the last ten years (i.e., from 2010 to the present), being this the unique filter to refine results. The reason to limit retrieval to this period is practical, as the newest publications should provide the most innovative advances yet based on consolidated fundamentals. The word combinations applied to the article's topic, title, abstract or keywords in the two used databases.

A total amount of 1633 articles were initially retrieved, 584 in WoS and 1049 in Scopus (Table 1). A preliminary selection was made by analysing the titles and discarding those differing from the purpose of this study. The main reason for rejection was discordance with the focus, even if there was some lexical matching. Although some articles were found twice, either by different searches of the same database or because they were in both of the databases used, it was decided to include them all to guarantee that the documents were systematically counted during the process, and discard them at a later stage. This procedure considered 351 articles to be eligible, and the original documents were downloaded using the institutional licenses for access to scientific databases. 66 had to be discarded for one of two reasons: some were written in languages we were unable to understand (mainly Korean and German) and others could not be downloaded.

Previous downloading, 99 of the papers were identified duplicated. Thus, a total of 186 documents were finally selected for review. 


\begin{tabular}{|c|c|c|c|c|c|c|c|c|}
\hline & \multicolumn{4}{|c|}{ Web of Science } & \multicolumn{4}{|c|}{ Scopus } \\
\hline & $\begin{array}{c}\text { Retriev } \\
\text { ed }\end{array}$ & Eligible & Discarded & Selected & Retrieved & Eligible & Discarded & Selected \\
\hline \multirow{2}{*}{$\begin{array}{l}\text { (1) acoustics "learning } \\
\text { processes" }\end{array}$} & 46 & 2 & 0 & 2 & 196 & 21 & 8 & 13 \\
\hline & & $4.4 \%$ & & $4.4 \%$ & & $10.7 \%$ & & $6.6 \%$ \\
\hline \multirow{2}{*}{$\begin{array}{l}\text { (2) acoustics "learning } \\
\text { environment" }\end{array}$} & 34 & 10 & 1 & 9 & 83 & 22 & 3 & 19 \\
\hline & & $29.4 \%$ & & $26.5 \%$ & & $26.5 \%$ & & $22.9 \%$ \\
\hline \multirow{2}{*}{ (3) classroom acoustics } & 504 & 126 & 15 & 111 & 770 & 170 & 39 & 131 \\
\hline & & $25 \%$ & & $22 \%$ & & $22.1 \%$ & & $17 \%$ \\
\hline \multirow{2}{*}{ TOTAL } & 584 & 138 & 16 & 122 & 1049 & 213 & 50 & 163 \\
\hline & & $23.6 \%$ & & $20.9 \%$ & & $20.3 \%$ & & $15.5 \%$ \\
\hline
\end{tabular}

Table 1. Results from the literature search in both databases

The filtering criteria used during a second phase was an attentive read of the abstracts to determine the main underlying focus and to classify the documents. As main focus, 38 papers studied classroom effects on teachers, 36 dealt with noise, 24 considered some cognitive process as main dependent variable, 24 reviewed reverberation effects, 20 studied systems or devices related to acoustics in classroom, 20 were devoted to concepts of the design of the classroom, 16 considered special needs of students, and 8 were about sustainability.

\subsection{Literature Analysis}

A narrative method was used to analyse the content of the retrieved documents and extract the relevant information. After an attentive reading of the publications content, the main ideas highlighted in line with the research purpose were identified. Then, a substantial amount of information was extracted from each of the documents, managed thematically using a word processor, and organised to structure the results. As some topics were recursive or more repetitive, information was extracted from the most relevant documents.

The final version of this review has been improved with purposeful additional references. These references are considered relevant and necessary to provide a more consistent foundation, as they match the inclusion criteria and provide better explanation of certain aspects. These references are indexed in WoS and/or Scopus despite not having appeared using the chosen keywords.

In the following section results are presented: first, the acoustic parameters in classrooms are explained, and then their effects on teachers and their effects on students are discussed.

\section{Acoustic Parameters in Classrooms}

Four important physical variables involved in the acoustic conditions in classrooms were identified. These four variables are closely related between them, and there is need to remember that masking is elementary to understand the reception of speech in noisy and reverberant settings. There are different environmental degradations and there is need to consider the distinction between competing signals leading to energetic masking and competing signals causing distortion without energetic masking (Mattys et al., 2012). In Figure 1 the main relationships between parameters extracted from the systematic literature review are presented, others could be also traced as all parameters are interlinked.

Noise is measured in decibels $(\mathrm{dB}-\mathrm{dBA})$ and it is the most significant parameter in the studies retrieved. It affects students and teachers as regards both learning performance and health issues, ranging from speaker's hoarseness or other voice problems caused by vocal effort, to worsening listener's diseases as hyperacusis (Tiesler et al. 2015; Augustyńska, Kaczmarska, Mikulski \& Radosz, 2010; Yassin, Almutairi, Alhajeri, Al-Fadhli, Al Rashidi \& Shatti, 2016). Reverberation time (RT) and the speech transmission index (STI) are generally proposed as the means of measuring how well students listen in classroom environments. There is frequent debate regarding which of these two commonly studied factors really 
represents the acoustic conditions in classrooms (Shams \& Ramakrishnan, 2012). In fact, reverberation is the most prominent factor in the literature and is also the most referenced acoustic measurement parameter (Mikulski \& Radosz, 2011; Gómez \& Barrigón, 2015). There is an important relationship between RT and STI. Increased RT can negatively impact speech intelligibility, and thus it must be optimal in order to make the teacher's speech intelligible (Shams \& Ramakrishnan, 2012). Speech clarity is the fourth main parameter, as it has an impact on student learning and attention (Drahorád, Saučuková, Drtina, Šedivý \& Schlosser, 2016).

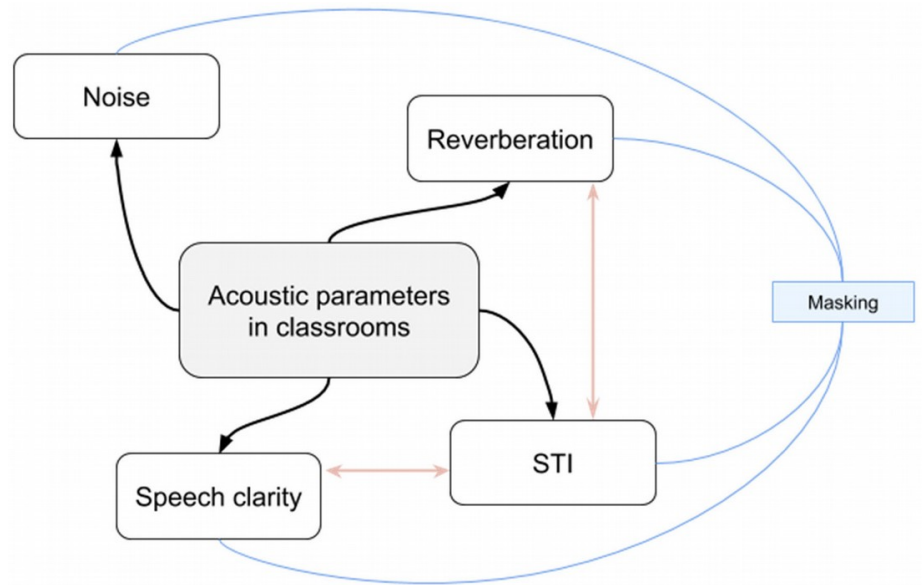

Figure 1. Main relationship between the themes extracted

\subsection{Background Noise and the Noises of Activity}

Noise can be stationary, fluctuating or semantic. In the classroom, noise can come from external inputs in the form of background noise or directly from students as noises of activity. Background noise may originate outdoors (the sounds of traffic, noises in corridors, noises from the playground) or indoors (passive noise from equipment such as heating, ventilation, air-conditioning and technological devices) (Bluyssen, 2017). These aspects contribute to an increase of noise regardless of the classroom activity. As explained in following sections, background noise has a direct effect in students (Persson-Waye, Fredriksson, Hussain-Alkhateeb, Gustafsson \& van Kamp, 2019) and teachers (Karjalainen, Brännström, Christensson, Sahlén \& Lyberg-Åhlander, 2020).

The noises of activity, on the other hand, come directly from the students themselves and include the handling of various objects, the shifting of chairs and tables, moving around and talking (Sala \& Rantala, 2016). Activity noise levels vary depending on the subject being taught, the number and age of the students and the pedagogical ideology (Sala \& Rantala, 2016). The World Health Organization (2015) specifies a standard background noise level of $35 \mathrm{dBA}$ during the teaching of lessons as a guideline for community noise. For proper speech transmission in the classroom, a measurement of $40 \mathrm{~dB}$ is considered noise pollution (Hadzi-Nikolova et al., 2013; Yassin et al., 2016).

\subsection{Reverberation Time}

Reverberation is the acoustic phenomenon of reflection that occurs in an enclosure when sound waves crash into the building material. The parameter that enables the reverberation of a room to be quantified is the reverberation time (RT). This is defined as the time in seconds required for the sound in an enclosure to decay by $60 \mathrm{~dB}$ after the sound source is turned off. The figure of $60 \mathrm{~dB}$ was set in 1922 by Sabine, who was the first to develop the RT formula (Zainudin, Mahamad, Saon \& Yahya, 2018). However, today there are four types of reverberation in architectural studies, these being decay time, RT (15), RT (20) and RT (30). RT20 is the most frequently used in practice. This means that the slope of the decay curve in the interval $-5 \mathrm{~dB}$ to $-25 \mathrm{~dB}$ determines the RT (Zainudin et al., 2018). 
Reverberation time is the most important factor in the acoustic quality of the classroom environment (Sarlati, Haron, Yahya, Darus, Dimon \& Athari, 2014). There is no universal, perfect reverberation for classroom performance. The optimal RT is zero when the speaker is closer to the listener than the noise source, but when the noise source is closer than the speaker, some reverberation is advantageous (Hodgson \& Nosal, 2002; McKellin, Shahin, Hodgson, Jamieson \& Pichora-Fuller, 2011). From this point there are specific numbers that must be avoided. In classrooms for flexible teaching methods with no more than 40 students, reverberation times should not be above 0.6 seconds (in conditions of full occupancy) or $0.7 \mathrm{~s}$ (in unoccupied furnished classrooms) (Garcia, Rasmussen \& Brunskog, 2014). The Acoustical Society of America standardized the maximum recommended RT60 level for classrooms at $0.5 \mathrm{~s}$, but the classroom acoustics standard is not strict and can be referenced by a state code, ordinance, or regulation (Rosenberg, 2010). This value can vary between countries according to their legislations.

As for the other parameters, experiments have shown that RT has a considerable effect on speech intelligibility in the classroom (Sodsri, 2012). Studies suggest that reverberation times that are slightly higher (between $0.45 \mathrm{~s}$ and $0.5 \mathrm{~s}$ in occupied classrooms) might be optimal, and that lower reverberation times are not necessarily better, based on vocal comfort considerations. In addition, reverberation times lower than $0.3 \mathrm{~s}$ might give rise to 'over-damping', i.e., an excessive attenuation of speech levels (Garcia et al., 2014).

\subsection{Speech Transmission Index}

Intelligibility is the technical name used to describe the pronunciation accuracy of speech. It is obvious that, in terms of learning, this parameter should be considered essential. The importance lies in particular in the intelligibility index that students get from the teacher, as this will have a direct impact on the learning they acquire.

The way teachers modify their speech (as regards speed, volume and/or frequency) makes this parameter difficult to measure. Nevertheless, it is important to determine the optimal conditions for good intelligibility regardless of the parameters of the human factor involving teachers modifying their speech. In this case, from a scientific point of view, we need to refer to the speech transmission index (STI). This is an objective, physical measurement of speech transmission quality. It is measured from 0 to 1 and indicates speech intelligibility, with 1 denoting the best transfer quality of speech and 0 denoting the worst. Study results confirm that the STI is a good predictor of the mean intelligibility score of any particular room (Gómez \& Barrigón, 2015). Anyhow, the STI is not related with fluctuating background noises (IEC 60268-16:2011, 2011).

As a measurement, the STI is used in various studies to determine a good rate of reverberation in the classroom. It is also found that higher reverberation times decrease speech intelligibility (Russo \& Ruggiero, 2018). If the reverberation time is between 0.4 and 0.6 seconds, intelligibility is considered to be "good" for normal speakers and listeners. In order for the STI of a common classroom to be considered "excellent" for students located at the back, the RT should not exceed 0.4. (Nijs \& Rychtáriková, 2011). Higher reverberation times would reduce speech intelligibility, which would in turn disengage students from learning (Garcia et al., 2014).

\subsection{Speech Clarity}

Speech clarity can refer to either teacher-student communication or to improved classroom performance. Clarity describes how clearly speech (or sound) can be heard by the listener, and increasing clarity is important for improving speech development in the classroom. It is related to late reflections, since these tend to make clarity of speech deteriorate. Therefore, the longer the reverberation time, the lower the clarity.

In order to achieve a good quality of speech clarity in classrooms, the amount of direct sound arriving at certain positions needs to be greater than the reflected sound (Youssef, Bard, Mahmoud \& Esa, 2014). This is based on the fact that the first reflections to arrive make the direct sound louder, while those that 
arrive later degrade the speech of sound. The spoken message thus becomes unclear and could affect classroom performance. The same paper points out an interesting relation between speech clarity and the frequency of sound waves. It was observed that speech clarity increased as the frequency increased, which means that speech clarity could be better for higher frequencies. In fact, a low level of clarity was found, especially between $125-2000 \mathrm{~Hz}$, and between these are the frequencies used in normal speech.

\section{Effects on Teachers}

The relation between noise, teacher voice and classroom acoustics has been widely explored in the last ten years (Rudner, 2018). Attention is focused on three areas exploring the health consequences of noise exposure: voice diseases, hearing diseases and stress-related health problems such as headaches and high blood pressure.

Although some studies point out the general health illnesses caused by noise (Hadzi-Nikolova et al., 2013; Tiesler et al., 2015; Seetha, Karmegam, Ismail, Sapuan, Ismail \& Moli, 2008; Kristiansen, Persson, Lund, Shibuya \& Nielsen, 2013; Cutiva \& Burdorf, 2015) and emotional problems such as stress, lack of energy, lack of interest in work and low motivation (Kristiansen et al., 2013; Kristiansen, Lund, Persson, Shibuya, Nielsen \& Scholz, 2014), most of them suggest that voice and vocal behavior is a key element.

The acoustics affect the teacher's voice production and therefore also classroom performance, because the teacher's voice is the most direct factor in communicating with students (Augustyńska et al., 2010). More specifically, Hunter, Cantor-Cutiva, van Leer, van Mersbergen, Nanjundeswaran, Bottalico et al. (2020) distinguished between vocal fatigue, vocal effort, vocal load and vocal loading. In any case, all of these concepts must be considered in classroom designs, considering concrete consequences like dysphonia or the Lombard effect. The most typical vocal dysfunction is dysphonia (Rincón \& Reyes, 2014), also known as hoarse voice, meaning that the voice sounds breathy, raspy, or strained involuntarily. Dysphonic voices are hoarse but can also be painful leading to an adverse behavior. It may have an effect on the listener the combination of a dysphonic teacher voice and poor acoustics. The Lombard effect, which is the involuntary increase of voice level in the presence of background noise, is commonly considered to be a determining factor in vocal dysfunctions (Rantala, Hakala, Holmqvist \& Sala, 2015). The Lombard sign affects both voice level and also the fundamental of the voice.

Background noise has negative effect on teachers' well-being (Karjalainen et al., 2020), but they are less affected by noise inside the classroom, where they can control it, than by outdoors background noise (Nusseck, Richter, Spahn \& Echternach, 2018). In addition, not all teachers respond to an increase in decibels in the work environment in the same way. In some cases when noise increases, the Lombard effect also increases, but this does not always happen. An important point is that teachers seem to raise their voices more in ambient noise than in the activity noise of daily classes (Rantala et al., 2015). Some results find no relation between classroom noise levels and the teacher raising their voice (Nusseck et al., 2018). This can be explained by teachers using the same sound pressure level regardless of the noise activity in the classroom.

As for the teacher's gender, there are significant differences in some results relating to the Lombard effect, in particular in the case of voice frequency. In some samples only the men modified their voice when ambient sound also increased, explained by the fact that the ambient sound is between 20 to $100 \mathrm{~Hz}$, and these data are closer to the men's frequency voice band (Rantala et al., 2015).

An excess of reverberation is evaluated negatively. Teachers working in classrooms with long reverberation times perceived their social climate to be more competitive and less relaxed and comfortable (Persson, Kristiansen, Lund, Shibuya \& Nielsen, 2013).

In light of hearing diseases, several researchers indicate the negative effect of noise on hearing. Apart from hearing loss, a commonly studied problem in classrooms is the hyperacusis, a disease consisting on auditory sensitivity to everyday sounds. This is experienced by $3,7 \%$ of children and up to $9,2 \%$ of adults in the world (Fackrell, Potgieter, Shekhawat, Baguley, Sereda \& Hoare, 2017), and in classroom settings it 
affects teachers as well as children (mostly those with autism disorders). Hyperacusis often coexists with tinnitus, which implies the perception of sound when no corresponding external sound exists. In the study held by Meuer and Hiller (2015), the conclusion that most teachers $(30 \%)$ suffered from all three hearing diseases (i.e., hyperacusis, tinnitus and hearing loss). Preschool teachers are likely to suffer from hearing-related symptoms and some authors highlight the need of preventative measures (Fredriksson, Kim, Torén, Magnusson, Kähäri, Söderberg et al., 2019).

\section{Effects on Students}

It is a challenge to interpret how acoustic conditions affect cognitive abilities due to limitations of controlling the noise in the evaluation (Klatte, Bergström \& Lachmann, 2013). Nevertheless, there is relevant data to be included in this review. Klatte et al. (2013) argue that there is evidence of the effects of noise on children's learning, especially in non-auditory areas such as short-term memory, reading and writing. In the learning processes there is a distinction between lexical and non-lexical tasks. Although the most critical results are related to lexical tasks, exposure to high noise has an effect on non-lexical tasks such as memory, reading ability, attention and motivation (Prodi \& Visentin, 2015) and numeracy (Dockrell \& Shield, 2012).

With reading tasks, reverberation must be significantly high for correlations to be found between reading speed and speech clarity (Puglisi, Prato, Sacco \& Astolfi, 2018), considering that long reverberation times make children perceive they are having less fun and being less happy with themselves (Astolfi, Puglisi, Murgia, Minelli, Pellerey, Prato et al., 2019). Children exposed to sound pressure levels above 80 dBA showed poorer performance, especially in the use of lexical abilities in both reading and writing (Santos et al., 2013).

Both males and females think noise is disturbing, but while more males think noise does not bother them, more females believe that noise makes it difficult for them to understand the teachers (Simion, 2018). Some differences can be found in relation to stress, anxiety, and health. Studies showed that students felt more anxious than stressed or depressed when the level of noise pollution was extreme (Sarlati et al., 2014). According to the children's opinions, well-being is not something influenced by the noise in school or in the classroom (Simion, 2018).

Most children state that noise bothers them, but there is no consensus regarding the students age. Whereas younger children are more bothered by noise in tasks involving speech perception and listening comprehension (Simion, 2018), other studies prove worse performance and a detrimental effect on older children when there is back-ground noise (Connolly, Dockrell, Shield, Conetta, Mydlarz \& Cox, 2019), being the 1 to 5 years old pupils the less affected by noise (Persson-Waye et al., 2019).

The noise perception also depends on the student's mood or attitude: in bad classroom acoustic conditions, the happiest students report perception of noise disturbance whereas the unhappy ones complain on bad classroom acoustics rather than associating the problem to their well-being (Astolfi et al., 2019).

Classroom acoustics have special effects on children with special needs such as language impairment (Sala, Hakala, Rantala, Holmqvist, Jonsdottir \& Rantanen et al., 2014), ADHD (Allen \& Pammer, 2018), autism (Kanakri et al., 2017) and hearing disorders (Iglehart, 2020). Also learning disabilities, mild to severe hearing loss or bilingualism are to be taken into account to consider classroom acoustics (Gheller, Lovo, Arsie \& Bovo, 2020). All the research in this sense is conclusive: these children are more affected by poor classroom acoustics and noise.

\section{Discussion and Conclusions}

Smart classrooms are learning spaces that cope with the forthcoming advances offered by the fourth industrial revolution (Mogas et al., 2020), which include the Internet of Things and Artificial Intelligence allowing cyber-physical systems (Zhong et al., 2017) to give personalized response to each students' needs. 
Although new possibilities may range up to automation of all processes carried out in classroom settings, and despite research is already reporting results (Abdel-Basset, Manogaran, Mohamed \& Rushdy, 2019) (Zawacki-Richter, Marín, Bond \& Gouverneur, 2019), this literature review on acoustics juxtaposed to the smart classrooms conceptualisation shows that we are still far from such advanced solutions to be implemented in schools. Short-term advances will rather consider systems for improving sound quality and reducing noise (Russo \& Ruggiero, 2018), systems for giving teachers insights into current needs (Jayahari et al., 2017), devices for controlling sound exposure (Guntha et al., 2016) and designs aimed at providing more sustainable settings (Tahsildoost \& Zomorodian, 2018).

Research presents the environmental factors like acoustics as main characteristics to be controlled in smart classrooms (Cech, 2016; Uzelac, Gligoric \& Krco, 2018) and tools like SoundOut could serve educators to measure the basic acoustic conditions of their classrooms (Mealings, 2019). This is basic to know which parameters are to be controlled and regulated in a smart classroom and this work presents a response from which interrelationships between agents (teachers and students), the learning environment (smart classroom) and the acoustical parameters are drawn below.

Reverberation time (RT), the speech transmission index (STI) and the speech clarity in a smart classroom should be combined to offer the most optimal environment taking into account that processes are very diverse: from different activities held by students to the voice of the teacher. The higher the background noise and reverberation are, the worse speech clarity and STI will be. Not least, the combined effect of the acoustics and the teacher's speech and voice on the student must also to be treated in depth. In this sense, when a noise source is closer of the student than the teacher when speaking, some reverberation is advantageous (Hodgson \& Nosal, 2002; McKellin et al., 2011). It is challenging for the smart classroom to have the systems and resources to detect the different types of noises and their source. In addition, the system should provide information about how to personalise the environment managing the particularities of the students as well as the different types of activity (for instance, identifying needs for theoretical lectures and for collaborative teamwork).

It also needs to be considered that STI and speech clarity are directly related to the teacher's voice as the source of sound emission. From this point of view, the control of the STI and speech clarity parameters would seem to be very useful in the emission of the teacher's voice and it might also be considered with the aim of improving the Lombard effect. But we have to consider the fact that the noise in classroom is so high that heavily affects the STI.

The phenomenon governing the reception of speech in a noisy and reverberant setting is mainly masking. In this review, masking appears in the background but it should be much better dealt when considering smart classrooms design. Classroom acoustics typically enhance the lower frequencies of sound, corresponding to the frequencies of most vowels, leading to a masking effect of speech, decreasing the clarity. Smart classrooms must include mechanisms to tackle this problem.

Sound conditions in a classroom may lead to several voice diseases for teachers as explained in section 4 . These difficulties (being caused by the environment or not) will at the same time affect directly communication with students and their performance. Therefore, a big concern in the smart classroom design refers to including tools to allow tracking teachers' voice health. Although external noise pollution can be improved by architectural design, this does not appear to be a viable aspect for individual automation. In order to automate noise control, we must take the total amount of $\mathrm{dB}$ (background and activity noise) into account. Smart classrooms must incorporate materials in their design to avoid unwanted noises, technological systems for greater control of any noises, the application of the noise traffic light in order to successfully reduce noise, and other innovations to provide better environmental conditions.

In regard of the students age, smart classrooms may host any grade, from children to higher education, but normally they are developed for older ones (secondary school to university). It should be better 
explored with younger children as they require better acoustic conditions to achieve sentence recognition equivalent to their older peers and adults (Wróblewski, Lewis, Valente \& Stelmachowicz, 2012).

The future classrooms can promote better and faster learning facilitating the education for sustainable development (Cebrián, Palau \& Mogas, 2020) because their design must be greener and more sustainable (Tahsildoost \& Zomorodian, 2018). The use of new materials and absorbent panels (Russo \& Ruggiero, 2018) are being considered in schools, to ensure quality of learners and teachers' performance.

The triad classroom acoustics, teachers and students in the context of school task and noise is a complex relationship, and for this reason this study was needed. No previous study interpreted these aspects regarding the future of the smart classrooms. However, our study presents certain limitation being the main its theoretical nature. Therefore, further research is needed to understand the triad by empirical experimentation regarding the different parameters and their possibilities within smart classrooms. There is still a special lack of research on the effects of automated systems. Another limitation is the lack of universal agreement on some acoustical parameters. For instance, the recommendations and legislation on reverberation time varies depending of the country. This does not allow to provide concrete values and thus makes it difficult to define standards for smart classrooms.

\section{Declaration of Conflicting Interests}

The authors declared no potential conflicts of interest with respect to the research, authorship, and/or publication of this article.

\section{Funding}

This research was partially funded by the Secretaria d'Universitats i Recerca del Departament d'Economia i Coneixement de la Generalitat de Catalunya, the European Union (EU) and the European Social Fund (ESF), grant number 2017 FI_B 00085.

\section{References}

Abdel-Basset, M., Manogaran, G., Mohamed, M., \& Rushdy, E. (2019). Internet of Things in smart education environment: Supportive framework in the decision-making process. Concurrency and Computation: Practice and Experience, 31(10), e4515. https://doi.org/10.1002/cpe.4515

Allen, R., \& Pammer, K. (2018). The impact of concurrent noise on visual search in children with ADHD. Journal of Attention Disorders, 22(14), 1344-1353. https://doi.org/10.1177/1087054715605913

Astolfi, A., Puglisi, G.E., Murgia, S., Minelli, G., Pellerey, F., Prato, A., et al. (2019). Influence of classroom acoustics on noise disturbance and well-being for first graders. Frontiers in Psychology, 10, 2736. https://doi.org/10.3389/fpsyg.2019.02736

Augustyńska, D., Kaczmarska, A., Mikulski, W., \& Radosz, J. (2010). Assessment of Teachers' Exposure to Noise in Selected Primary Schools. Archives of Acoustics, 35(4), 521-542. https://doi.org/10.2478/v10168-010-0040-2

Bezerra, L., \& Gaudiot, D.M.S.F. (2012). The deaf and the classroom design: a contribution of the built environmental ergonomics for the accessibility. 18th World congress on Ergonomics - Designing a sustainable future, 41(1), 3663-3668. https://doi.org/10.3233/WOR-2012-0007-3663

Bluyssen, P.M. (2017). Health, comfort and performance of children in classrooms - New directions for research. Indoor and Built Environment, 26(8), 1040-1050. https://doi.org/10.1177/1420326X16661866

Bosch, R. (2018). Designing for a Better World Starts at School. Saxo Publish.

Cebrián, G., Palau, R., \& Mogas, J. (2020). The Smart Classroom as a means to the development of ESD methodologies. Sustainability, 12(7), 3010. https://doi.org/10.3390/su12073010 
Cech, P. (2016). Smart Classroom Study Design for Analysing the Effect of Environmental Conditions on Students' Comfort. Intelligent Environments, 21, 14-23. https:/ / doi.org/10.3233/978-1-61499-690-3-14

Connolly, D., Dockrell, J., Shield, B., Conetta, R., Mydlarz, C., \& Cox, T. (2019). The effects of classroom noise on the reading comprehension of adolescents. The Journal of the Acoustical Society of America, 145(1), 372-381. https://doi.org/10.1121/1.5087126

Cutiva, L.C., \& Burdorf, A. (2015). Effects of noise and acoustics in schools on vocal health in teachers. Noise \& Health, 17(74), 17-22. https://doi.org/10.4103/1463-1741.149569

Dockrell, J.E., \& Shield, B. (2012). The Impact of Sound-Field Systems on Learning and Attention in Elementary School Classrooms. Journal of Speech, Language, and Hearing Research, 55(4), 1163-1176. https://doi.org/10.1044/1092-4388(2011/11-0026)

Drahorád, J., Saučuková, K., Drtina, R., Šedivý, J., \& Schlosser, M. (2016). Limiting Acoustic Conditions the Transfer of Information in the Digitalized Classroom. International Conference on Electrical Engineering and Automation (ICEEA 2016). https://doi.org/10.12783/dtetr/iceea2016/6687

Esteve, F., Duch, J., \& Gisbert, M. (2014). Los aprendices digitales en la literatura científica: Diseño y aplicación de una revisión sistemática entre 2001 y 2010. Píxel-Bit, 45, 9-21.

Fackrell, K., Potgieter, I., Shekhawat, G.S., Baguley, D.M., Sereda, M., \& Hoare, D.J. (2017). Clinical interventions for hyperacusis in adults: a scoping review to assess the current position and determine priorities for research. BioMed Research International, 2723715. https://doi.org/10.1155/2017/2723715

Fredriksson, S., Kim, J.L., Torén, K., Magnusson, L., Kähäri, K., Söderberg, M., et al. (2019). Working in preschool increases the risk of hearing-related symptoms: a cohort study among Swedish women. International Archives of Occupational and Environmental Health, 92(8), 1179-1190. https://doi.org/10.1007/s00420-019-01453-0

Garcia, D.P., Rasmussen, B., \& Brunskog, J. (2014). Classroom acoustics design for speakers' comfort and speech intelligibility: a European perspective. Proceedings of Forum Acusticum.

Gheller, F., Lovo, E., Arsie, A., \& Bovo, R. (2020). Classroom acoustics: Listening problems in children. Building Acoustics, 27(1), 47-59. https://doi.org/10.1177/1351010X19886035

Gisbert, J.P., \& Bonfill, X. (2004). ¿Cómo realizar, evaluar y utilizar revisiones sistemáticas y metaanálisis? Gastroenterol Hepatol, 27(3), 129-149. https://doi.org/10.1016/S0210-5705(03)79110-9

Gómez, V., \& Barrigón, J.M. (2015). Analysis of intelligibility and reverberation time recommendations in educational rooms. Applied Acoustics, 96, 1-10. https://doi.org/10.1016/j.apacoust.2015.03.001

Guntha, R., Hariharan, B., \& Rangan, P.V. (2016). Analysis of Echo Cancellation Techniques in Multi-Perspective Smart Classroom. International Conference on Advances in Computing, Communications and Informatics (ICACCI). IEEE. https:// doi.org/10.1109/ICACCI.2016.7732197

Hadzi-Nikolova, M., Mirakovski, D., Zdravkovska, M., Angelovska, B., \& Doneva, N. (2013). Noise Exposure of School Teachers - Exposure Levels and Health Effects. Archives of Acoustics, 38(2), 259-264. https://doi.org/10.2478/aoa-2013-0031

Hodgson, M., \& Nosal, E.M. (2002). Effect of noise and occupancy on optimal reverberation times for speech intelligibility in classrooms. The Journal of the Acoustical Society of America, 111(2), 931.

https://doi.org/10.1121/1.1428264

Hunter, E.J., Cantor-Cutiva, L.C., van Leer, E., van Mersbergen, M., Nanjundeswaran, C. D., Bottalico, P., et al. (2020). Toward a Consensus Description of Vocal Effort, Vocal Load, Vocal Loading, and Vocal Fatigue. Journal of Speech, Language, and Hearing Research, 63(2), 509-532.

https://doi.org/10.1044/2019_JSLHR-19-00057 
Iannace, G., Trematerra, A., \& Trematerra, P. (2014). Acoustic correction using green material in classrooms located in historical buildings. Acoustics Australia / Australian Acoustical Society, 41(3), $213-218$. https://doi.org/10.5755/j01.sace.3.4.4708

IEC 60268-16:2011. (2011) Sound system equipment - Part 16: Objective rating of speech intelligibility by speech transmission index. Available at: https://webstore.iec.ch/publication/1214

Iglehart, F. (2020). Speech perception in classroom acoustics by children with hearing loss and wearing hearing aids. American Journal of Audiology, 29(1), 6-17. https://doi.org/10.1044/2019_AJA-19-0010

Jayahari, K.R., Beenu, B., \& Bijlani, K. (2017). Delivery monitoring system for teachers' voice in traditional classrooms and automatic controlling system in smart/remote classrooms. In IEEE International Conference on Smart Technologies and Management for Computing, Communication, Controls, Energy and Materials (ICSTM). https://doi.org/10.1109/ICSTM.2017.8089136

JISC (2006). Designing spaces for effective learning: A guide to 21st century space design (1-36). HEFCE.

Kanakri, S.M., Shepley, M., Varni, J.W., \& Tassinary, L.G. (2017). Noise and autism spectrum disorder in children: An exploratory survey. Research in Developmental Disabilities, 63, 85-94.

https://doi.org/10.1016/j.ridd.2017.02.004

Karjalainen, S., Brännström, J.K., Christensson, J., Sahlén, B., \& Lyberg-Åhlander, V. (2020). A Pilot Study on the Relationship between Primary-School Teachers' Well-Being and the Acoustics of their Classrooms. International Journal of Environmental Research and Public Health, 17, 2083. https://doi.org/10.3390/ijerph17062083

Kinshuk, \& Graf, S. (2012). Ubiquitous Learning. In Seel, N.M. (Ed.), Encyclopedia of the Sciences of Learning. Springer. https://doi.org/10.1007/978-1-4419-1428-6_224

Klatte, M., Bergström, K., \& Lachmann, T. (2013). Does noise affect learning? A short review on noise effects on cognitive performance in children. Frontiers in Psychology, 4, 578.

https://doi.org/10.3389/fpsyg.2013.00578

Koper, R. (2014). Conditions for effective smart learning environments. Smart Learning Environments, 1, 5. https://doi.org/10.1186/s40561-014-0005-4

Kristiansen, J., Lund, S.P., Persson, R., Shibuya, H., Nielsen, P.M., \& Scholz, M. (2014). A study of classroom acoustics and school teachers' noise exposure, voice load and speaking time during teaching, and the effects on vocal and mental fatigue development. International Archives of Occupational and Environmental Health, 87(8), 851-860. https://doi.org/10.1007/s00420-014-0927-8

Kristiansen, J., Persson, R., Lund, S.P., Shibuya, H., \& Nielsen, P.M. (2013). Effects of Classroom Acoustics and Self-Reported Noise Exposure on Teachers' Well-Being. Environment and Behavior, 45(2), 283-300. https://doi.org/10.1177/0013916511429700

Lehtniemi, N. (2016). Toda la verdad sobre la escuela finlandesa. Consejo de Promoción de Finlandia.

López, M. (2019). The Integration of digital devices into learning spaces according to the needs of primary and secondary teachers. TEM Journal, 8(4), 1351-1358. https://doi.org/10.18421/TEM84-36

Mattys, S.L., Davis, M.H., Bradlow, A.R., \& Scott, S.K. (2012). Speech recognition in adverse conditions: A review. Language and Cognitive Processes, 27(7-8), 953-978. https://doi.org/10.1080/01690965.2012.705006

McKellin, W.H., Shahin, K., Hodgson, M., Jamieson, J., \& Pichora-Fuller, M.K. (2011). Noisy zones of proximal development: Conversation in noisy classrooms. Journal of Sociolinguistics, 15(1), 65-93. https://doi.org/10.1111/j.1467-9841.2010.00467.x

Mealings, K. (2019). Validation of the SoundOut Room Acoustics Analyzer App for Classrooms: A New Method for Self-Assessment of Noise Levels and Reverberation Time in Schools. Acoustics Australia, 47, 277-283. https://doi.org/10.1007/s40857-019-00166-1 
Mendes, A.L.F., Lucena, B.T.L., De Araújo, A.M.G.D., Melo, L.P.F., Lopes, L.W., \& Silva, M.F.B.L. (2016). Teacher's voice: vocal tract discomfort symptoms, vocal intensity and noise in the classroom. CoDAS, 28(2), 168-175. https://doi.org/10.1590/2317-1782/20162015027

Meuer, S.P., \& Hiller, W. (2015). The impact of hyperacusis and hearing loss on tinnitus perception in German teachers. Noise Health, 17(77), 182-190. https://doi.org/10.4103/1463-1741.160682

Mikulski, W., \& Radosz, J. (2011). Acoustics of Classrooms in Primary Schools - Results of the Reverberation Time and the Speech Transmission Index Assessments in Selected Buildings. Archives of Acoustics, 36(4), 777-793. https://doi.org/10.2478/v10168-011-0052-6

Mogas, J., Palau, R., Lorenzo, N., \& Gallon, R. (2020). Developments for Smart Classrooms: Schools Perspective and Needs. International Journal of Mobile and Blended Learning, 12(4), art. 3.

https://doi.org/10.4018/IJMBL.2020100103

Mogas, J., Palau, R., Sanromà, M., \& Lázaro, J.L. (2019). Smart classroom, an inclusive space to attend to educational diversity. In El Homrani, M., Báez, D.E., \& Ávalos, I. (Coords.), Inclusión y Diversidad: intervenciones socioeducativas. Wolters Kluwer. https://tienda.wolterskluwer.es/p/inclusion-y-diversidadintervenciones-socioeducativas

Nijs, L., \& Rychtáriková, M. (2011). Calculating the Optimum Reverberation Time and Absorption Coefficient for Good Speech Intelligibility in Classroom Design Using U50. Acta Acustica united with Acustica, 97(1), 93-102. https://doi.org/10.3813/AAA.918390

Nusseck, M., Richter, B., Spahn, C., \& Echternach, M. (2018). Analysing the vocal behaviour of teachers during classroom teaching using a portable voice accumulator. Logopedics Phoniatrics Vocology, 43(1), 1-10. https://doi.org/10.1080/14015439.2017.1295104

Palau, R., \& Mogas, J. (2019). Systematic literature review for a characterization of the smart learning environments. In Cruz, A.M. \& Aguilar, A.I. (Eds.), Propuestas multidisciplinares de innovación e intervención educativa (55-71). Universidad Internacional de Valencia.

https://www.universidadviu.es/modelo-de-investigacion/

Peng, Z.E., \& Wang, L.M. (2019). Listening Effort by Native and Nonnative Listeners Due to Noise, Reverberation, and Talker Foreign Accent During English Speech Perception. Journal of Speech, Language, and Hearing Research, 62(4), 1068-1081. https://doi.org/10.1044/2018_JSLHR-H-17-0423

Persson, R., Kristiansen, J., Lund, S.P., Shibuya, H., \& Nielsen, P.M. (2013). Classroom acoustics and hearing ability as determinants for perceived social climate and intentions to stay at work. Noise \& Health, 15(67), 446-453. https:// doi.org/10.4103/1463-1741.121254

Persson-Waye, K., Fredriksson, S., Hussain-Alkhateeb, L., Gustafsson, J., \& van Kamp, I. (2019). Preschool teachers' perspective on how high noise levels at preschool affect children's behavior. PLoS ONE, 14(3), e0214464. https://doi.org/10.1371/journal.pone.0214464

Prodi, N., \& Visentin, C. (2015). Listening efficiency during lessons under various types of noise. The Journal of the Acoustical Society of America, 138(4), 2438. https://doi.org/10.1121/1.4932053

Puglisi, G.E., Prato, A., Sacco, T., \& Astolfi, A. (2018). Influence of classroom acoustics on the reading speed: A case study on Italian second-graders. The Journal of the Acoustical Society of America, 144. https://doi.org/10.1121/1.5051050

Rantala, L.M., Hakala, S., Holmqvist, S., \& Sala, E. (2015). Classroom Noise and Teachers' Voice Production. Journal of Speech, Language, and Hearing Research, 58(5), 1397-1406.

https://doi.org/10.1044/2015_JSLHR-S-14-0248

Reinten, J., Braat-Eggen, E., Hornikx, M., Kort, H.S.M., \& Kohlrausch, A. (2017). The indoor sound environment and human task performance: A literature review on the role of room acoustics. Building and Environment, 123, 315-332. https://doi.org/10.1016/j.buildenv.2017.07.005 
Rincón, M., \& Reyes, J.A. (2014). Analysis of teacher working environment: factors that influence the voice. Audiology - Communication Research, 19(4), 399-405. https://doi.org/10.1590/S231764312014000400001337

Rosenberg, G.G. (2010). Classroom Acoustics. Seminars in Hearing, 31(3), 188-202. https://doi.org/10.1055/s-0030-1262325

Roy, K.P. (2010). Green Rating Systems and Classroom Acoustic Design. In Proceedings of 20th International Congress on Acoustics, ICA.

Rudner, M. (2018). Effects of background noise, talker's voice, and speechreading on speech understanding by primary school children in simulated classroom listening situations. The Journal of the Acoustical Society of America, 144, 1976. https://doi.org/10.1121/1.5068629

Russo, D., \& Ruggiero, A. (2018). Choice of the optimal acoustic design of a school classroom and experimental verification. Applied Acoustics, 146, 280-287. https://doi.org/10.1016/j.apacoust.2018.11.019

Sala, E., \& Rantala, L. (2016). Acoustics and activity noise in school classrooms in Finland. Applied Acoustics, 114, 252-259. https://doi.org/10.1016/j.apacoust.2016.08.009

Sala, E., Hakala, S., Rantala, L.M., Holmqvist, S., Jonsdottir, V.I., \& Rantanen, K. (2014). Acoustics: A basic element in learning. In Proceedings of Forum Acusticum.

Santos, J.F., Ramos, A.P., \& Seligman, L. (2013). Comparative analysis of performance in reading and writing of children exposed and not exposed to high sound pressure levels. CoDAS, 25(3), 274-281. https://doi.org/10.1590/S2317-17822013000300014

Sarlati, S., Haron, Z., Yahya, K., Darus, N., Dimon, N., \& Athari, P. (2014). The Importance of Acoustic Quality in Classroom. Jurnal Teknologi, 70(7), 71-76. https://doi.org/10.11113/jt.v70.3581

Seetha, P., Karmegam, K., Ismail, M.Y., Sapuan, S.M., Ismail, N., \& Moli, L.T. (2008). Effects to teaching environment of noise level in school classrooms. Journal of Scientific \& Industrial Research, 67, 659-664.

Sekine, R., Asai, Y., \& Egi, H. (2018). Designing a System of Generating Sound Environment for Promoting Verbal Communication in Classroom. In Egi, H., Yuizono, T., Baloian, N., Yoshino, T. Ichimura, S. \& Rodrigues, A. (Eds), Collaboration Technologies and Social Computing. CollabTech 2018. Lecture Notes in Computer Science, 11000. Cham: Springer. https://doi.org/10.1007/978-3-319-98743-9_8

Shahroom, A.A., \& Hussin, N. (2018). Industrial Revolution 4.0 and Education. International Journal of Academic Research in Business and Social Sciences, 8(9), 314-319. https://doi.org/10.6007/IJARBSS/v8-i9/4593

Shams, S., \& Ramakrishnan, R. (2012). Acoustic metrics for classroom performance- A literature review. Proceedings of the Acoustics Week in Canada, 40(3).

Simion, A. (2018). Classroom acoustics in the social and emotional development of primary school children. In The European Proceedings of Social \& Behavioural Sciences. https://doi.org/10.15405/epsbs.2018.06.11

Sodsri, C. (2012). Effects of classroom reverberation and listeners' locations to speech intelligibility. In 9th International Conference on Electrical Engineering/Electronics, Computer, Telecommunications and Information Technology. https://doi.org/10.1109/ECTICon.2012.6254178

Tahsildoost, M., \& Zomorodian, Z.S. (2018). Indoor environment quality assessment in classrooms: An integrated approach. Journal of Building Physics, 42(3), 336-362. https://doi.org/10.1177/1744259118759687

Tiesler, G., Machner, R., \& Brokmann, H. (2015). Classroom Acoustics and Impact on Health and Social Behaviour. Energy Procedia, 78, 3108-3113. https://doi.org/10.1016/j.egypro.2015.11.765

Trematerra, A., \& Lombardi, I. (2017). Green Materials for Sound Absorption. Key Engineering Materials, 729, 63-67. https://doi.org/10.4028/www.scientific.net/kem.729.63 
Uzelac, A., Gligoric, N., \& Krco, S. (2018). System for recognizing lecture quality based on analysis of physical parameters. Telematics and Informatics, 35(3), 579-594. https://doi.org/10.1016/j.tele.2017.06.014

van der Kruk, Y., Wilson, W.J., Palghat, K., Downing, C., Harper-Hill, K., \& Ashburner, J. (2017). Improved Signal-to-Noise Ratio and Classroom Performance in Children with Autism Spectrum Disorder: a Systematic Review. Review Journal of Autism and Developmental Disorders, 4(3), 243-253. https://doi.org/10.1007/s40489-017-0111-7

Vangrieken, K., Meredith, C., Packer, T., \& Kyndt, E. (2017). Teacher communities as a context for professional development: A systematic review. Teaching and Teacher Education, 61, 47-59. https://doi.org/10.1016/j.tate.2016.10.001

Wang, S., \& Zhang, D. (2019). Student-centred teaching, deep learning and self-reported ability improvement in higher education: Evidence from Mainland China. Innovations in Education and Teaching International, 56(5), 581-593. https://doi.org/10.1080/14703297.2018.1490662

Woolner, P., \& Hall, E. (2010). Noise in Schools: A Holistic Approach to the Issue. International Journal of Environmental Research and Public Health, 7, 3255-3269. https://doi.org/10.3390/ijerph7083255

World Health Organization. (2015). School environment: Policies and current status. WHO Regional office for Europe. http://www.euro.who.int/ data/assets/pdf file/0009/276624/School-environment-Policies-currentstatus-en.pdf?ua $=1$

Wróblewski, M., Lewis, D.E., Valente, D.L., \& Stelmachowicz, P.G. (2012). Effects of reverberation on speech recognition in stationary and modulated noise by school-aged children and young adults. Ear and Hearing, 33(6), 731-744. https://doi.org/10.1097/AUD.0b013e31825aecadabout:blank

Yassin, M.F., Almutairi, H., Alhajeri, N., Al-Fadhli, F., Al Rashidi, M.S., \& Shatti, T. (2016). Assessment of noise exposure and associated health risk in school environment. International Journal of Environmental Science and Technology, 13(8), 2011-2024. https://doi.org/10.1007/s13762-016-1035-y

Youssef, R.S., Bard, D., Mahmoud, A.E., \& Esa, N.M. (2014). Acoustical quality assessment of lecture halls at Lund University, Sweden. 43rd International Congress and Exposition on Noise Control Engineering (Internoise 2014), Australian Acoustical Society (1382-1391).

Zainudin, F.L., Mahamad, A.K., Saon, S., \& Yahya, M.N. (2018). Prediction of Classroom Reverberation Time using Neural Network. Journal of Physics: Conference Series, 995, 012028.

https://doi.org/10.1088/1742-6596/995/1/012028

Zawacki-Richter, O., Marín, V.I., Bond, M., \& Gouverneur, F. (2019). Systematic review of research on artificial intelligence applications in higher education - where are the educators? International Journal of Educational Technology in Higher Education, 16, 39. https://doi.org/10.1186/s41239-019-0171-0

Zhong, R.Y., Xu, X., Klotz, E., \& Newman, S.T. (2017). Intelligent manufacturing in the context of industry 4.0: A Review. Engineering, 3(5), 616-630. https://doi.org/10.1016/J.ENG.2017.05.015

Published by OmniaScience (www.omniascience.com)

Journal of Technology and Science Education, 2021 (www.jotse.org)

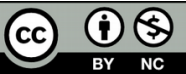

Article's contents are provided on an Attribution-Non Commercial 4.0 Creative commons International License. Readers are allowed to copy, distribute and communicate article's contents, provided the author's and JOTSE journal's names are included. It must not be used for commercial purposes. To see the complete licence contents, please visit https://creativecommons.org/licenses/by-nc/4.0/. 